\title{
Afet Sonrası İyileştirme Planı Hazırlanması
}

\author{
Hasan ÇOBAN ${ }^{1 *}$
}

\section{Öz}

Türkiye bulunduğu coğrafi konum itibarı ile başta deprem, su baskını ve heyelan olmak üzere doğal-kaynaklı afet riski altında bulunmaktadır. Muhtemel bir afet sonrasında en az can ve mal kaybı yaşanması için afet öncesinde önleme, zarar azaltma ve afetlere hazırlık çalışmaları ile afet sonrasında acil müdahale, iyileştirme ve yeniden inşa çalışmalarını kapsayacak şekilde etkin bir afet yönetiminin uygulanması gerekmektedir. Afet yönetiminde bu güne kadar afet farkındalık eğitimleri verilmesi, afet tehlike haritaları hazırlanması, binalarda iyileştirme yapılması, Türkiye Afet Müdahale Planının hazırlanması gibi afetlere hazırlık ve afet sonrası acil müdahale çalışmaları yapılmış olmakla birlikte risk azaltma ve afet sonrası iyileştirme konularında kapsamlı bir çalışma maalesef yapılamamıştır. Afet sonrası iyileştirme çalışmalarının yararlı olabilmesi için afet olmadan önce, muhtemel bir afet sonrasında uygulanacak olan afet sonrası iyileştirme planlarının nasıl hazırlanacağının usul ve esasların belirlenmesi, muhtemel afet bölgeleri için iyileştirme planı taslağının hazırlanması ve iyileştirme planının nasıl ve hangi kuruluşun sorumluluğunda yürütüleceğinin bilinmesi gerekir. Marmara bölgesinde olması muhtemel bir deprem sonrasında, bir deprem senaryo çalışması yapılmış olan İstanbul'da can ve mal kaybının oldukça yüksek olacağı tahmin edildiğinden İstanbul afet sonrası iyileştirme planı taslağının ivedilikle hazırlanmasında yarar görülmektedir.

Anahtar Kelimeler: Afet, Afet Yönetimi, Afet Sonrası İyileştirme Planı, Afetlere Karşı Hassas Alanlar,

\section{Preparation of Post Disaster Recovery Plan}

\begin{abstract}
\footnotetext{
${ }^{1}$ Uzman, Cumhurbaşkanlığı - Strateji ve Bütçe Başkanlığı, Ankara

* Illgili Yazar/Corresponding author: hasancoban@yahoo.com

Gönderim Tarihi / Submission Date: 10.09.2019

Kabul Tarihi / Acception Date: 19.12.2019
}

Turkey is under the natural-sourced disaster risk such as primarily earthquakes, floods and landslides by geographic location. To prevent the loss of life and property after a possible disaster, an effective disaster management system should be implemented including predisaster prevention, harm reduction, disaster preparedness, emergency response, improvement and reconstruction works. Even if the disaster preparedness and disaster emergency response work such as giving disaster awareness training, disaster hazard map preparation, making retrofitting in buildings and reparation of Turkey Disaster Response Plan have been performed, a comprehensive risk mitigation plan and disaster recovery plan were not prepared before disaster stage. An effective recovery plan studies should start before disaster during mitigation and prepare with all stakeholders under the coordination of a responsible organization. Along with the history of Istanbul, there were many damaging earthquakes. For this reason, a scenario study was conducted in 2009 to estimate the result 
of the possible Marmara earthquake affecting Istanbul near the feature, therefore the Istanbul Recovery Plan can be prepared based on the scenario study.

Key Words: Disaster, Disaster Management, Post-Disaster Recovery Plan, Disaster Prone Areas,

\section{AFET YÖNETIMI}

Türkiye bulunduğu coğrafi konum ve jeolojik yapısı itibariyle başta deprem, su baskını ve heyelan olmak üzere doğal-kaynaklı afet riski altında bulunmaktadır. Muhtemel bir afet sonrasında en az can ve mal kaybı yaşanması amacıyla afet öncesinde risk azaltma ve afetlere hazırlık çalışmaları ile afet sonrasında müdahale, iyileştirme ve yeniden inşa (Erkan A. 2010: 6) çalışmalarını kapsayan (Şekil 1'de verilen) etkin bir afet yönetiminin uygulanması gerekli görülmektedir.

Afetler nedeniyle büyük kayıpların oluşmaması için afet tehlike ve risklerinin belirlenmesi, afetleri önleyici tedbirlerin alınması, risk azaltıcı yatırımların yapılması gibi faaliyetlere risk azaltma çalışması (Erkan, 2010: 10) denilmektedir.

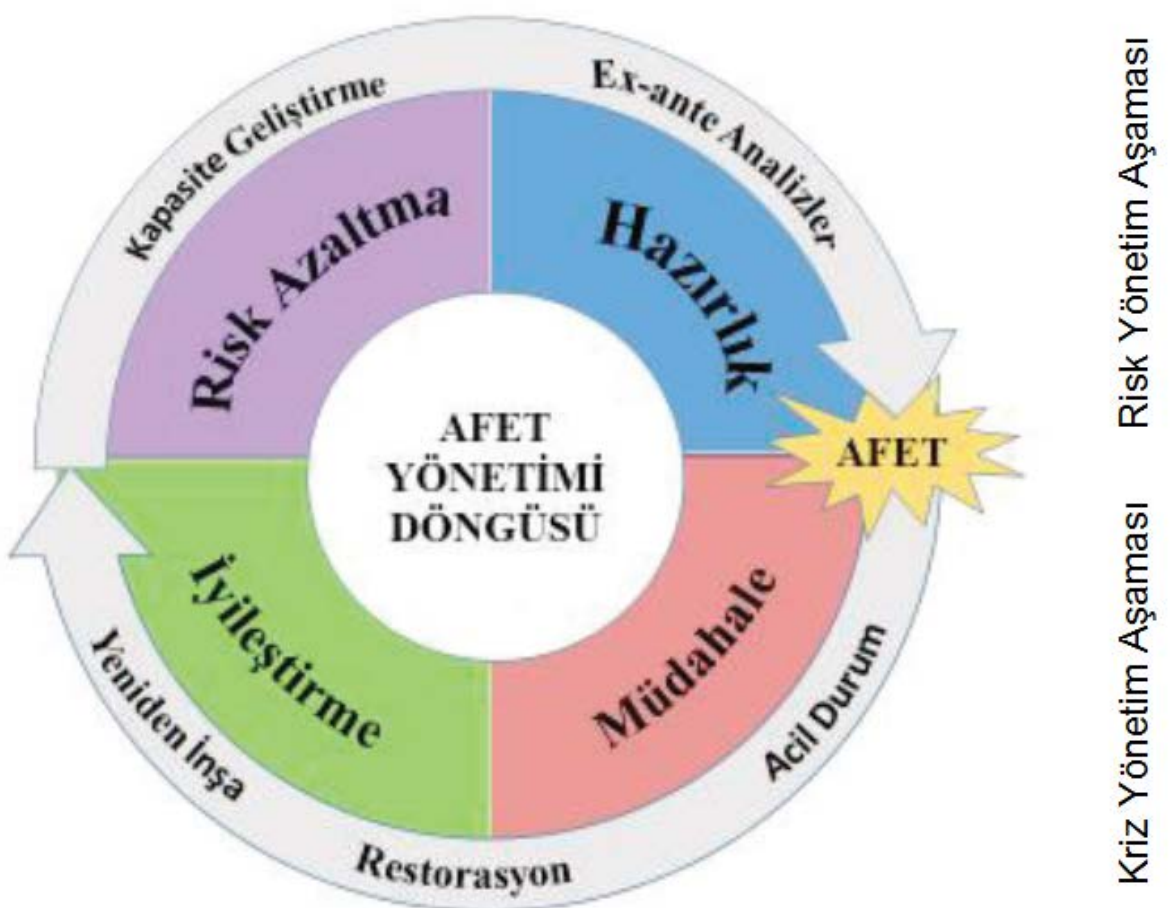

Şekil 1: Kapsamlı Afet Yönetim Döngüsü (Erkan A. (2010: 9), Özmen R. (2016: 10) (Acil durum, Arama-Kurtarma-Geçici Barınma faaliyetlerini ifade etmektedir.)

Afetlere karşı zamanında, hızlı ve etkili müdahale edebilmek için afet öncesinde gerekli planlama, eğitim ve tatbikatların yapılması, erken uyarı sistemlerinin kurulması, acil yardım malzemelerinin depolanması, halkın afetlerle karşı bilgilendirilmesi gibi faaliyetlere afetlere hazırlık çalışması (Erkan, 2010: 10) denilmektedir.

Afetin oluşundan hemen sonra başlayıp afetin yol açtığı kayıp ve zararların büyüklüğüne bağlı olarak 1-2 aylık süre içinde gerçekleştirilen ve afetten etkilenen yerleşim yerlerinde arama - kurtarma çalışmalarının yapılması, yaralıların tedavi edilmesi, açıkta kalanların 
geçici barınma, beslenme, güvenlik ve moral desteği gibi hayati intiyaçların karşılanması gibi faaliyetlere müdahale çalışması (Erkan, 2010: 10) denilmektedir (Şekil 1). Afet olunca hemen başlatılan acil müdahale çalışmalarının tüm kamu kurum ve kuruluşları tarafından koordineli bir şekilde yürütülmesiyle günlük hayatın mümkün olan en kısa zamanda normale çevrilmesi sağlanabilmektedir.

Yaşanılan afetlerde 1-2 aylık müdahale çalışması yapıldıktan sonra afetten etkilenenlerin intiyaçlarının karşılanması ve günlük hayatın normale döndürülmesi için afet bölgesinde afete dayanıklı konutların yapılması, altyapıların ve üst yapıların iyileştirilmesi ya da yenilerinin yapılması; tarım, hayvancılık, sanayi, ticaret, eğitim, sağılk gibi alanlarda destek sağlanarak ekonomik ve sosyal hayata canlılık kazandırılması; toplumun muhtemel afetlere karşı dayanıklılığının sağlanması; afete maruz bölgenin eski durumundan daha iyi olacak şekilde kalkındırıması çalışmalarına iyileştirme çalışması denilmektedir (Erkan, 2010: 10).

\section{AFET SONRASI IYILEŞTIRME ÇALIŞMALARI}

Afet sonrasında yapılan iyileştirme çalışmaları afet risklerinin azaltılması, afetlere hazırlık, afet sonrası müdahale gibi afet yönetiminin ayrılmaz bir parçasıdır. İyileştirme aşaması, genellikle müdahale aşamasından hemen bitiminde başlayıp yıllarca devam edebilen bir süreçtir.

Afet sonrasında yapılan iyileştirme ve yeniden yapılandırma çalışmalarının amacı afetten etkilenenlerin ve afet bölgesindeki ekonomik ve sosyal hayatın afetten önceki normal duruma, hatta daha gelişmiş bir duruma getirilmesinin sağlanmasıdır (Gökçe, Tetik, 2012: 47). İyileştirme aşaması, afetin panik havası geçtikten sonra günlük hayatın yeniden düzenlenmesi ve canlandırılması için yoğun çalışmaların ve düzenlemelerin yapılması gereken bir süreçtir.

İyileştirme çalışması, kısa dönemde hayatın normal akışı içinde toplumun ihtiyaç duyduğu elektrik, su, kanalizasyon, doğalgaz ve haberleşme gibi çağdaş altyapılarının yenilenmesi ile uzun dönemde afetten etkilenenlerin normal hayata dönmelerini sağlayacak sistemin yeniden yapılandırılmasına yönelik faaliyetleri kapsamaktadır.

Afet sonrası iyileştirme çalışması afet yönetimi kapsamında yürütülen çalışmaların en kapsamlısı olup vatandaşlar, kuruluşlar ve çıkar grupları tarafından en fazla müdahil olunan ve maliyeti en fazla olan bir çalışmadır (Özmen, 2016: 17). Ancak, afet yönetiminde bu güne kadar afet farkındalık eğitimlerinin verilmesi, afet tehlike haritalarının hazırlanması, binalarda iyileştirme yapılması, Türkiye Afet Müdahale Planının hazırlanması gibi afetlere hazırlık ve afet sonrası müdahale için çalışmalar yapılmış olmakla birlikte risk azaltma ve afet sonrası iyileştirme konularında kapsamlı bir çalışma maalesef yapılamamıştır.

Afet sonrası iyileştirme çalışmalarının yapılması oldukça önemli bir süreç olmasına rağmen afet sonrası iyileştirme planı hazırlanması afet yönetimi alanında en az önem verilen konulardan biridir. Maalesef, afet olduktan sonra, afet sonrası iyileştirme planı yapılmaya çalışıldığından ve planın nasıl yapılacağının usul ve esasları bilinmediğinden afet sonrasında bir iyileştirme planının yapılması yöneticileri içinden çıkılmaz bir kararsızlığa düşürmektedir. Ayrıca, afete uğrayanların beklentilerinin bir an önce karşılanması yönündeki toplumsal baskılar artıı̆ından (Özmen, 2016: 56) ve yöneticilerin bu baskılar karşısında gerekli iyileştirme çalışmalarını plan yapılmasını beklemeden günübirlik kararlarla yerine getirmek 
istediklerinden iyileştirme planı yapımı genellikle kesintiye uğramaktadır. Bu nedenle, yaşanılan her büyük afet sonrasında acıların bir an önce dindirilmesinin baskısı altında plansız bir şekilde aceleyle alınan kararlarla iyileştirme çalışmaları yürütülmektedir.

Afet sonrası iyileştirme planlarının nasıl hazırlanacağının usul ve esaslarının afet öncesinde belirlenmiş olması gerekir. Belirlenen usul ve esaslar çerçevesinde afet olması muhtemel olan yerleşim yerleri ve bölgeler için afet senaryosu çalışması yapılıp taslak iyileştirme planları hazırlanmalı ve afet olduktan sonra uğranılan zararın ön tespitinin ve etki değerlendirilmesinin yapılması ile taslak plandaki parametreler değiştirilip sorumlu kuruluş tarafından uygulamaya geçirilmesi gerekmektedir.

İyileştirme çalışmalarının, afetten etkilenenlerin ihtiyaçları en az afetten önceki veya mümkünse daha ileri bir düzeyde karşılanana kadar devam etmesi gerekmektedir.

Depremler başta olmak üzere afetler, sadece ev ve işyerlerini tahrip etmemekte, elektrik, su, doğalgaz, telefon hatları, yollar, köprüler, boru hatları, barajlar ve limanlar gibi ülkenin kritik önemi haiz altyapılarının kullanılamaz hale gelmesine neden olmaktadır.

Afet sonrasında yapılan iyileştirme çalışmalarının sadece afetten zarar görenlerinin konut ihtiyacının karşılanması ile sınırlı tutulmaması, altyapıların, kamu hizmetlerinin, sosyal hayatın, iş hayatının ve günlük hayatın afet öncesinden daha iyi olacak şekilde yeniden düzenlenmesi gerekmektedir.

1999 yılında Marmara Bölgesinde ve 2011 yılında Van'da yaşanılan depremlerden sonra iyileştirme planı yapılmadığından afet bölgelerinde afet sonrası müdahale çalışmalarının süresi ve kapsamı genişletilerek hayatın normale döndürülebilmesi için günü birlik kararlarla gerekli iyileştirme çalışmaları yapılmıştır. Özelikle Marmara depreminden sonra iyileştirme planı olmadan yapılan faaliyetler çok sayıda kurum ve kuruluş tarafından müstakil olarak yürütülmüştür. Bu durum kurumlar arası işbirliği ve eşgüdümü zora sokmuştur. Koordinasyon eksikliği hemen hemen her alanda ortaya çıkmıştır. Kurumlar yürüttükleri faaliyetlerle birbirlerini olumsuz manada etkilediği durumlar da olmuştur.

Marmara bölgesinde olması muhtemel bir deprem sonrasında İstanbul'daki altyapılarda ve binalarda olabilecek zararların, yaralı ve can kaybının oldukça yüksek olacağı tahmin edilen bir deprem senaryo çalışması 2009 yılında yapılmıştır (İstanbul Büyük Şehir Belediyesi, 2009). Bu senaryo çalışmasının günün şartlarına göre yenilenerek ve yeni deprem senaryosu doğrultusunda karşılaşılacak zararın boyutuna bağlı olarak İstanbul İyileştirme Planı taslağı hazırlanarak İstanbul'u etkileyecek bir depremde yaşanılacak zararın kısa sürede telafi edilmesi ve hayatın normale çevrilmesi için etkin bir iyileştirme çalışması yapılabilecektir.

\subsection{Afet sonrası iyileştirme çalışmalarının kademeleri}

Bir afet yaşanmasından sonra yürütülen iyileştirme çalışmaları düzenli ve planlı bir şekilde yapıldığı takdirde afete uğrayan yerlerin eski durumundan daha iyi bir duruma getirileceği aşikârdır. Afet sonrası iyileştirme süreci 4 aşamada ele alınabilir (Özmen, 2016: 40). Bu evrelerdeki süreler afetin büyüklüğüne, etkilediği alana ve iyileştirme için ayrılan ekonomik kaynaklara bağlı olarak değişebilmektedir. 
Müdahale Dönemi: Birkaç hafta sürer. Arama-kurtarma yapılması, geçici barınma intiyaçlarının (çadır-yiyecek-içecek) temin edilmesi, hasar tespiti yapılması ve enkaz kaldırma işlerini kapsar.

Normale Dönme Dönemi: Birkaç ay sürer. Sınırlı da olsa ekonomik ve sosyal faaliyetlere geri dönülmesine ilişkin çalışmaları kapsar.

Yeni Yerleşimlerin Kurulması Dönemi: 1-2 yıl sürebilir. Risk değerlendirmeye dayalı yerleşime uygun alanların seçilmesine, kalıcı konutların yapılmasına, ekonomik ve sosyal hayatın eskisinden daha iyi hale getirilmesine ilişkin çalışmaları kapsar.

Kalkınmaya Yönelik Yeniden İnşa Dönemi: 1 ila 5 yıl sürdürülebilen ve afete uğrayan bölgenin kalkındırılmasına yönelik çalışmaları kapsar.

\subsection{Afet sonrası iyileştirme planının yapılmasında izlenecek yol}

Afet sonrası iyileştirme çalışmalarının verimli olabilmesi için afet olmadan önce, muhtemel bir afet sonrasında yapılacak iyileştirme çalışmalarının çerçevesini belirleyecek olan iyileştirme planlarının nasıl hazırlanacağının usul ve esasların belirlenmesi, muhtemel afet bölgeleri için iyileştirme planı taslağının hazırlanması, iyileştirme planının hangi kuruluşun sorumluluğunda yürütüleceğinin çıkarılacak bir mevzuat ile belirlenmesi gerekir.

Afet olan yerleşim yerlerinin yeniden inşa edilmesi için Cumhurbaşkanlığı veya Bakanlar Kurulu Kararı ile özerk bir afet bölgesi iyileştirme merkezi kurularak veya bir kamu kuruluşu sorumlu koordinatör kuruluş olarak görevlendirilerek hazırlanmış bir iyileştirme planı doğrultusunda gerekli iyileştirilmesi çalışmalarının yapılması mümkün olacaktır.

Çıkarılacak mevzuatın afet bölgesi iyileştirme merkezi başkanı, yönlendirme komisyonu üyeleri, merkezin sekreterya işlerinin hangi kuruluşun yapacağı gibi hususlara açıklık getiren ve merkezin çalışma usul ve esaslarını belirleyen bir içerikte olması gerekir.

5902 Sayılı Afet ve Acil Durum Yönetim Başkanlığı İle İlgili Bazı Düzenlemeler Hakkında Kanunun 38. Maddesi 1. Bendi d) paragrafında "Afetten etkilenen bölgelerde, kamu kurum ve kuruluşları, mahalli idareler, üniversiteler ve sivil toplum kuruluşları ile işbirliği içinde afet sonrası yeniden yapılanma ve iyileştirme planlarını hazırlamak, hazırlanan planların uygulanmasını koordine etmek, uygulamaya ilişkin ilerleme raporlarını hazırlamak" şeklinde iyileştirme planı yapılmasına ilişkin hüküm yer almaktadır.

7269 Umumi Hayata Müessir Afetler Dolayısıyla Alınacak Tedbirlerle Yapılacak Yardımlara Dair Kanunda afet sonrası iyileştirmelere ilişkin yapılacak çalışmalar acil müdahale, arama kurtarma, hasar tespiti, geçici iskân, hak sahiplerinin tespiti, yeni yerleşim yerlerinin temini ve planlaması, kalıcı konutların yapımı ve hak sahiplerine teslimi gibi sadece konut yapımına ilişkin hükümler bulunmaktadır.

7269 Sayılı Kanunda afet sonrasında yapılacak iyileştirme çalışmaların neler olacağı açık olarak belirtilmesine; 5902 Sayılı Kanunda ile afet sonrasında yeniden yapılanma ve iyileştirme planlarının hazırlanması, uygulanması ve uygulamanın izlenmesi görevi belirlenmiş olmasına rağmen; halen afet sonrası iyileştirme çalışmalarının nasıl bir yol izlenerek yapılacağına ilişkin bir yönetmelik ya da usul ve esaslar belirlenmemiş olması ülkemiz için bir eksikliktir. 
Afet sonrası iyileştirme çalışmalarında yanlış anlaşılan hususlardan biri de iyileştirme çalışmasının sadece afetten etkilenenlere kalıcı konut yapılması olarak algılanmasıdır.

Afet sonrası yeniden yerleştirme çalışmaları afet olan yerin doğal (coğrafi, jeolojik) yapısına ve afetin büyüklüğüne bağlı olarak afet olmadan önce yaşanılan yerde ya da yeni bir yerde yapılabilir. Ancak, afet konutlarının jeolojik verilere göre yer seçiminde, mimarisinin belirlenmesinde, hak sahiplerine dağıtımında, altyapıların eksikliği, eski yerleşim yerine uzaklığı, sosyal ve idari hizmetlerin eski duruma göre yetersizliği gibi yaşanılan sıkıntılar iyileştirme planı olmaksızın yeniden yerleştirme yapılmasının sonucunda ortaya çıkmaktadır.

\subsection{Etkin bir iyileştirme planı hazırlanabilmesi için yapılması gerekenler}

- Afet sonrası iyileştirme planı hazırlanması için ek mevzuat çıkarılmalıdır.

- Afet sonrası iyileştirme planı hazırlanmasına ilişkin usul ve esaslar hazırlanmalıdır.

- Afet sonrası iyileştirme planının hazırlanmasından ve uygulanmasından sorumlu olacak kurum belirlenmiş olmalıdır.

- Afet sonrası geçici konutların ve kalıcı iskânın nerede olacağı afet olmadan önce belirlenmiş olmalıdır. Bu yapılmazsa afet sonrasında kalıcı konutların ve yeni yerleşim yerinin belirlenmesi zorlaşmakta ve çoğunlukla yerbilimleri verilerine dayalı risk değerlendirilmesi yapılmadığından yanlış yerler seçilmektedir.

- Hasar tespitinin yapılması, kamulaştırma, altyapıların yenilenmesi ve yeniden yerleşim faaliyetlerindeki kurumsal sorumluluklar belirlenmiş olmalıdır.

- Afet öncesinde afet sonrası iyileştirme çalışması yapabilecek akredite firmalar belirlenmiş olmalıdır.

\subsection{Afet sonrası iyileştirme planı hazırlanmasında dikkate alınacak hususlar}

- Halkın katılımı sağlanmalıdır.

- Tarihi yerleşimlerin nasıl iyileştirileceğine açıklık getirilmelidir.

- Planı uygulayacak kuruluş Cumhurbaşkanı Kararı ile belirlenmelidir.

- İyileştirme planları bilimsel verilere dayalı gerçekçi bir afet senaryosu esas alınarak hazırlanmalıdır.

- İyileştirme planı taslağı afet olmadan önce hazırlanmalıdır.

- Plan gerçekçi ve uygulanabilir olmalıdır.

\subsection{Afet sonrası iyileştirme planının genel çerçevesi}

- Olan afetin etkilerini ayrıntılı olarak gösteren mevcut durum ortaya konulmalıdır.

- Öncelik alanları iyi belirlenmelidir.

- Planın amacı ve hedefleri belirlenmelidir.

- Planın uygulanmasında İzlenecek stratejiler belirlenmelidir.

- İyileştirme planı kapsamında yapılacak faaliyetlerin hangi kuruluşlar tarafından yapılacağı, ne zaman yapılacağı, işbirliği yapılacak kuruluşları, maliyetlerini ve elde edilecek sonuçları gösterecek şekilde bir eylem planı hazırlanmalıdır.

- İyileştirme Planının bileşenlerini oluşturan alt çalışmaları için, ulaştırma planı, enerji temin planı gibi alt planlar hazırlanmalıdır.

\subsection{Afet Sonrası iyileştirme planının etkin bir şekilde uygulanabilmesinin şartları}

- Hasar tespiti zamanında yapılmalıdır, 
- Siyasi irade desteği olmalıdır.

- Etkin koordinasyon sağlanmalıdır.

- Yeterli kaynak ayrılmalıdır.

- İyileştirme döneminde risk azaltmaya ilişkin politikalar yasalaştırılmalıdır.

- İyileştirme planın uygulanması ve yönetimi için gerekli personel, yer, makine/teçhizat, ulaşım ve benzeri imkânlar sağlanmalıdır.

- Planın uygulanması konusunda kamuoyu bilgilendirilmelidir.

- İyileştirme Planının uygulanmasında edinilen tecrübeler ve yaşanılan aksaklıklar dikkate alınarak 4-5 yılda bir düzeltme yapılmalıdır.

- Yerleşim yerlerinin yeniden yapılandırılmasında halkın katıımı sağlanmalıdır.

\subsection{Afet sonrası iyileştirme planının uygulanmasında karşılaşılan sıkıntılar}

- Mevzuata dayalı yaşanılan sıkıntılar.

- İyileştirme uygulamasına yönelik standartların yetersiz olması.

- Yeniden yerleşim için belirlenen yerlere ilişkin anlaşmazlıklar ve mülkiyet hakları.

- Yaşanılan afetten sonra aynı yerde başka afetlerin yaşanması.

- Afet sonrası iyileştirme planları ile kalkınma planlarının birbirine karıştırıması.

- İyileştirme planında görev alan kuruluşlardaki personel değişiklikleri.

- Karar vericiler ve paydaşlar arasında iletişim eksikliği.

- İyileştirme çalışmalarında kısa vadeli, aceleci ve geçici çözümlere başvurulması.

- Afet risklerine duyarlı mekânsal planlama eksikliği.

- Yetersiz iyileştirme stratejileri ile yeni risklerin oluşturulması.

Afet sonrası yapılan iyileştirme çalışmaları aslında bir sonraki afetler için yapılan hazırlık çalışmaları niteliğindedir. Afet sonrası iyileştirme planlarında afetle ilgili kurumların üstleneceği görevler, koordinasyonun nasıl sağlanacağı, kaynakların nasıl kullanılacağı, izleme ve değerlendirmenin nasıl yapılacağı gibi hususların açık bir şekilde belirlenmesinin gerekli olduğu düşünülmektedir. Afet sonrası iyileştirme planı uygulanırken yaşanılan tecrübelere bağlı olarak günün şartlarına 4-5 yılda bir yenilenerek belirlenen iyileştirme hedeflerine ulaşılması mümkün olacaktır.

\section{SONUÇ-DEĞERLENDIRME}

Yaşanan bir afet sonrasında yeniden inşa ve yapılaşma süreci afetin günlük hayatı etkilediği belirli bir zaman dilimi geçtikten sonra başlatımalıdır. Yeniden inşa edilen yapılarda dayanıklı malzeme kullanıldığından emin olunmalı, yapı tekniğine uygun ve gerekli standartları taşıyan binalar inşa edilmelidir.

Afet sonrası iyileştirme planının afet öncesinde hazırlanması iyileştirme çalışmalarının daha etkin uygulanabilmesini sağlamaktadır. Önceden karara bağlanmış politikaların uygulanması daha kolay olurken, iyileştirme çalışmalarında ani kararlar alınarak yapılan ve plansız yürütülen faaliyetler karmaşıklığa neden olabilmektedir.

İyileştirme planlarının nasıl hazırlanacağının usul ve esaslarının belirlenmediği ve taslak iyileştirme planı yapılmadığı sürece büyük bir afet olmuş olsa yine eskisi gibi acil müdahale yapılıp acıların bir an önce dindirilmesi için aceleyle plansız bir şekilde iyileştirme çalışmalarının yapılacağı açıktır. 
Afet sonrası iyileştirme çalışmaları kapsamında muhtemel bir afetin risk ve zararları dikkate alınarak afet öncesinde katılımcı bir süreç ile iyileştirme planlarının hazırlanması ve afet sonrasından geliştirilen iyileştirme planın uygulanmasından sorumlu olan kuruluşun belirlenmiş olması gerekir.

İyileştirme planları uygulanarak, afet zararlarının giderilmesi, toplumsal sürdürülebilirliğin sağlanması ve gelecekte olması muhtemel diğer afetler karşısında toplumun ve yerleşim yerlerinin sosyoekonomik açıdan dirençli hale getirilmesi sağlanabilir.

İstanbul gibi deprem riski yüksek olan yerleşim yerleri için deprem sonrasında karşılaşılacak zararları gösteren senaryo çalışması yapılarak afet sonrası iyileştirme planı taslaklarının hazırlanması ile muhtemel bir deprem sonrasında yapılacak iyileştirme çalışmalarının etkin bir şekilde yürütülmesi sağlanabilecektir.

\section{Kaynakça}

Çoban H. (2014), Marmara Depremi Sonrası İstanbul İyileştirme Planı (İstanbul'un Yeniden İnşa Edilmesi), http://www.hasancoban.com/afet/Istanbul\%20iyilestirme-plani-2014.04.11.pdf.

ERKAN A. (2010), Afet Yönetiminde Risk Azaltma ve Türkiye'de Yaşanan Sorunlar (DPT, Uzmanlık Tezi), Ankara: Mülga DPT yayınları.

Gökçe O, Tetik Ç. (2012), Teoride ve Pratikte Afet Sonrası İyileştirme Çalışmaları, Ankara: Afet ve Acil Durum Yönetimi Başkanlığı Yayınları.

İstanbul Büyükşehir Belediyesi (2009), Muhtemel İstanbul Depreminin sonuçlarına ilişkin son rapor.

Kobe İyileştirme Planı (1995), Japonya.

Özmen R. (2016), Afet Sonrası İyileştirme Sürecinde Devletin Rolü, Ankara: Mülga Kalkınma Bakanlığı Yayınları. 